\title{
Vidas móveis
}

ELLIOTT, A.; URRY, J. Mobile Lives. London: Routledge, 2010. 194p.

\section{Resumo}

O sociólogo britânico John Urry dedicou sua vida acadêmica à reflexão de como os constantes avanços tecnológicos - nos transportes e na comunicação, principalmente - têm transformado a sociedade. Em 2010, com a colaboração de Anthony Elliott, Urry lança o livro Mobile Lives, no qual objetiva analisar sociologicamente como os já referidos avanços influenciam as múltiplas e novas maneiras que as identidades são constituídas e organizadas, através de vários espaços e no decorrer do tempo. Esse texto tem como objetivo destacar os principais pontos do referido livro, cotejando-o com as obras anteriores de Urry por considerar que constituem o mesmo esforço de consolidar o chamado paradigma das mobilidades. Palavras-chave: Mobilidades. John Urry. Identidade.

\footnotetext{
*Fundação Getúlio Vargas (FGV), Rio de Janeiro - RJ, Brasil.
} 


\section{Mobile Lives}

\section{Abstract}

The British sociologist John Urry has devoted his academic life to think on how the constant technological advances - in transport and communications, especially - have transformed the society. In 2010, with the collaboration of Anthony Elliott, Urry publishes Mobile Lives, which aims to analyze sociologically, how the aforementioned technological advances affect the multiple and new ways that identities are formed and organized through various spaces and in the course time. This text aims to highlight the main points of this book, comparing it with the previous work of Urry considering that constitute the same effort to consolidate the mobilities paradigm.

Keywords: Mobilities. John Urry. Identities.

Muitos são os caminhos possíveis para analisar as questões sociais contemporâneas. Na última década, o sociólogo britânico John Urry dedicou-se a consolidar o que ele chama de paradigma das mobilidades. Consistiria, basicamente, em uma teoria geral do mundo social baseada, sobretudo, na capacidade de movimento, seja de pessoas, de produtos, ou de ideias. As principais argumentações acerca do paradigma das mobilidades estão presentes nos livros Sociology beyond Societies (2000) e Mobilities (2007), ainda não traduzidos para o português. Embora a obra de John Urry seja vasta e reconhecida internacionalmente, somente o The Tourist Gaze, de 1990, foi publicado no Brasil, sob o título O Olhar do Turista. Ainda que não tenha foco no paradigma das mobilidades, John Urry reconhece que esse livro capturou parte do processo de pulverização de fronteiras, que estavam sendo transcendidas através dos múltiplos fluxos de pessoas, imagens de lugares, produtos e serviços. ${ }^{1}$

\footnotetext{
${ }^{1}$ Entrevista com John Urry. Estudos históricos. Rio de Janeiro, v. 24, n. 47, Junho de 2011.
} 
O sociólogo australiano Anthony Elliot dedicou-se a estudar teoria social e psicologia, explorando as interseções entre essas áreas. Nesse diapasão, destaca-se o Subject to ourselves (1996) e Social theory since Freud (2004). Além do livro em questão lançado com Urry, Elliot lançou mais dois livros em parceria com outros autores: The new individualism (2005), com Charles Lemert, e o recente On society (2012), com Bryan Turner.

Lançado em 2010, Mobile Lives reitera, de certa maneira, os esforços teóricos antes empreendidos por John Urry nos já referidos Sociology beyond Societies e Mobilities. Por mais que nesses livros o autor tenha alvitrado o paradigma das mobilidades com uma boa base empírica, o Mobile Lives - como evidencia o título - dispõe-se a analisar a questão das mobilidades em clara interface com a experiência da vida contemporânea. Para tanto, os autores debruçam-se sobre a realidade de diferentes indivíduos a fim de evidenciar a inerência da mobilidade ao contexto social.

Os autores prefaciam o livro destacando seu principal objetivo:

'Mobile lives' faz a conexão da análise sociológica de diferentes formas de viagem, transporte, turismo e comunicação com as múltiplas e novas maneiras que as identidades são constituídas e organizadas através de vários espaços e no decorrer do tempo (Elliott; Urryt, 2010, p.VIII, tradução nossa).

Por mais que todos os capítulos tenham interseções e abordem realmente as vidas móveis, parece ser proveitoso analisar cada capítulo separadamente, para que não seja negligenciada a relevância de nenhum deles. A análise aqui desenvolvida não pretende abordar diretamente nenhum dos exemplos usados pelos autores. Um ponto marcante de todos os exemplos é a sua complexidade, o que faz parecer insipiente e inócua qualquer tentativa de simplificá-los. Ou seja, acredita-se que se os exemplos apresentados no livro fossem mencionados sem a argumentação necessária, eles deixariam de ser bons exemplos. 
No primeiro capítulo do livro, os autores destacam que, no ano de 1800, os cidadãos dos Estados Unidos deslocavam-se, em média, 50 metros por dia; enquanto que hoje eles viajam 50 quilômetros. Argumentase que esse aumento é incontestavelmente responsável pela ampliação da emissão de gás carbônico. O impacto ambiental - e social - do aumento do efeito estufa é trabalhado mais detalhadamente no último capítulo, quando são apresentados possíveis cenários para o futuro.

É interessante ressaltar a referência que os autores fazem a Zygmunt Bauman. De certa maneira, há muito em comum entre a liquidez generalizada de Bauman e a concepção das mobilidades. Ainda que os focos analíticos sejam bastante diferentes, destaca-se o livro lançado em 2005 por Bauman, Liquid Life. Ambos os livros trazem para o centro das suas análises esse caráter fluído do mundo contemporâneo em interface com a construção das identidades.

Destaca-se também o conceito de network capital. Essa ideia já havia sido trabalhada previamente por Urry, mas devido a sua relevância para o paradigma das mobilidades, ela é apresentado novamente. O autor utiliza a interpretação que Bourdieu fez do conceito de Marx sobre capital. Para além dos capitais econômico, cultural, social e simbólico, o autor incluiu o capital de rede. Os autores remontam os oito elementos básicos para a constituição e reprodução do capital de rede, que seriam: 1) um arranjo de documentos, vistos, dinheiro e qualificações que permitem que o indivíduo locomova-se seguramente entre cidades e países; 2) outras pessoas - colegas de trabalho, amigos ou familiares - que ofereçam convites, acolhimento e encontros; 3) capacidade de movimento em diversos ambientes, incluindo a habilidade, competência e interesse em usar telefones celulares, SMS, e-mail, internet, Skype etc.; 4) acesso amplo a informações e contatos; 5) equipamentos de comunicação; 6) lugares apropriados e seguros para encontros e reuniões; 7) acesso a meios 
de transporte e tecnologias de comunicação; 8) tempo e outros recursos para monitorar os sete elementos anteriores, além da capacidade de remediar eventuais falhas. (p. 10 e 11)

Em linhas gerais, capital de rede refere-se à capacidade de engendrar e manter relações sociais com pessoas que não estão necessariamente próximas e que podem gerar benefícios emocionais, financeiros e práticos. É necessário frisar que as mobilidades em si não significam nada, a questão mais determinante é a capacidade do indivíduo de usá-las em prol de si mesmo e daqueles que pretende beneficiar.

Ainda em caráter introdutório, os autores apresentam os cinco tipos de mobilidades, frisando a interdependência entre elas: a) a viagem corpórea de pessoas motivadas por trabalho, lazer, família, prazer, migração e fuga; b) o movimento físico dos objetos para os produtores, revendedores e consumidores, bem como o envio e recebimento de presentes e souvenirs; c) viagem imaginativa proporcionada pelas imagens dos lugares; d) viagem virtual, muitas vezes em tempo real, transcendendo a distância geográfica e social; e) viagem comunicativa, que consiste na comunicação de pessoas através de mensagens, textos, cartas, telefone, fax e celular (p. 15 e 16).

Esse paradigma enfatiza a complexa reunião entre essas diferentes mobilidades que fazem e mantêm contingencialmente as conexões através de distâncias múltiplas e variadas. Isto enfatiza as interconexões entre estas cinco mobilidades, bem como os discursos que priorizam uma ou outra mobilidade (tal como a crença que determinado negócio deve ser feito' face-to-face'). (p. 16, tradução nossa).

No segundo capítulo, os autores aprofundam o debate sobre as relações entre novas tecnologias e novas mobilidades. O argumento básico é que essas tecnologias são fundamentais para a vida em movimento e, para evidenciar essa relação, eles apresentam o conceito de mobilidades 
miniaturizadas. Este conceito é referente aos equipamentos eletrônicos que permitem a comunicação e o entretenimento enquanto os indivíduos estão em movimento. Refere-se, claramente, aos celulares, tocadores de mp3, notebooks, aparelhos portáteis de DVD. Os autores alvitram que esse tipo de tecnologia tem sido fundamental para o desenvolvimento das sociedades contemporâneas e que contribui para a intensificação da vida em movimento.

Na mesma linha de pensamento, ressaltam a importância do walkman para a emergência histórica desse tipo de tecnologia. Além de possibilitar a audição de música simultânea à outra atividade, o walkman permitia que o indivíduo transportasse-se psicologicamente para outra realidade. De certa maneira, todas essas mobilidades miniaturizadas propõem-se a possibilitar que o indivíduo esteja - metaforicamente - em um lugar diferente daquele em que ele se encontra. O celular põe em contato pessoas espacialmente separadas. Um notebook conectado à internet permite que a pessoa trabalhe, socialize e entretenha-se em qualquer lugar que esteja.

Outra questão relevante é a relação que desenvolveu-se entre essas tecnologias e o processo de construção da identidade. O eu individual não apenas usa ou ativa tecnologias digitais no seu dia-a-dia. Ao contrário, o eu - em condições de intensa mobilidade - encontra-se profundamente mergulhado nas redes tecnológicas, bem como remodelado por sua influência. Percebe-se, sobretudo, o desenvolvimento de uma dependência dessas tecnologias.

Os autores tentam abordar, de maneira imparcial, como essas novas tecnologias influenciam transformações sociais. Para tanto, citam Norman H. Nie e outros colegas, que já haviam apontado que a crítica social deveria afastar-se das categorizações genéricas sobre as tecnologias móveis serem boas ou ruins para a sociabilidade e focar em como especificas 
implantações tecnológicas afetam o eu e as relações interpessoais (p.42). De certa maneira, essa postura perdura ao longo de todo livro: os autores priorizam a análise social em detrimento de uma postura normativa frente a um cenário de mudanças.

No capítulo 3, Networks and inequalities, os autores exploram o campo das redes de maneira notável. Para sedimentar este ponto de vista, baseiamse nas proposições de outros autores, como Manuel Castells, Luc Boltanski e Eve Chiapello, Yochai Benckler, Charlie Leadbetter, Barry Wellman, entre outros. Parece ser digno de ênfase a pesquisa empírica de Duncan Watts para sustentar a tese do mundo pequeno. Elliot e Urry não apresentam detalhes da pesquisa, porém esta teoria supõe que entre qualquer pessoa do planeta e outra, há apenas seis pessoas, alguém que conhece alguém que conhece alguém e assim por diante (Watts apud Elliot; Urry, 2010, p. 49).

Itera-se ainda que, de certa maneira, todos os autores supracitados trabalham com a ideia de uma sociedade na qual a rede (network) adquire suma importância. Com base nessas premissas, Elliott e Urry examinam sociologicamente os impactos do networking. Abordam como o capital de rede é construído e que, tal como o capital de Marx, é objeto de poder e desigualdade, podendo ser operado para beneficiar algum grupo social à custa de outros grupos. A mobilidade de alguns depende de que outros tantos estejam imóveis. Sublinha-se, sobretudo, que os autores postulam que o desenvolvimento dessas redes e da comunicação à distância não substituiria o contato face a face, mas, sim, serviria como uma nova alternativa.

No capítulo 4, The globals and their mobilities, é apresentada uma nova elite: The globals. A lista dos ricos feita pela Forbes em 2008 identificou 1.125 bilionários, que acumulam juntos $U \$$ 4,4 trilhões. Baseando-se em Bauman, os autores destacam ainda que o surgimento dessa nova super elite deve ser compreendido em um contexto de transformação de uma organizada modernidade sólida para uma desorganizada modernidade líqui- 
da, essa transformação contribuiu para a reestruturação do trabalho: surgimento de novas profissões e novos processos de divisão social, sobretudo.

Retomando o capítulo 3, ressalta-se que o que sustenta o fluido mundo de trabalho dos globais são os muitos funcionários que permanecem imóveis. Há sempre um regime de imobilidade de muitos que dá suporte à vida móvel de poucos. Outro ponto interessante é que essa nova elite global sustenta um estilo de vida luxuoso, baseado em serviços e bens de consumo de alto valor.

A vida do 'global' pode ser pensada como um tipo de desempenho estético. O poder e o prestígio das elites globais são menos categorias sociais ou estruturas pré-existentes do que um tipo de identidade que tem que ser promulgada, realizada e representada para os outros. (p. 79, tradução nossa.)

Seguindo essa linha de pensamento, os autores fazem outra menção a Pierre Bourdieu, ao referirem-se à distinção. Segundo eles, as práticas sociais de distinção se baseiam cada vez mais no simbolismo do luxo, da exclusividade e do dispendioso para legitimar a separação entre as elites e os demais grupos. Desse modo, o consumo é um instrumento de construção de identidade e de reiteração de status social. É notável também que o estilo de vida dessa elite acaba sendo tomado pelo senso comum e pela mídia como um tipo ideal, fazendo com que outras pessoas sonhem com tal realidade. Podese aferir que a mobilidade é também uma prática social, ou, pelo menos, parte constituinte do habitus - nos moldes de Bourdieu - dos globais.

No capítulo 5, Mobile relationships, os autores abordam a questão dos relacionamentos - amorosos, principalmente - à distância.

Dada a disponibilidade da telefonia móvel, da internet, da viagem barata de carro e avião, não é nenhuma surpresa que mais pessoas fiquem fascinadas com as novas maneiras de explorar suas vidas privadas e relações intimas à distância (p. 85, tradução nossa). 
Na tentativa de elucidar como se tornaram possíveis as relações afetivas à distância, os autores chamam atenção para o que seria a morte da distância. Os constantes avanços tecnológicos aumentam significantemente o fluxo de pessoas, objetos, informações, mensagens e imagens; a ponto de o longe deixar de ser um obstáculo intransponível. Evidentes reflexos da globalização, que, no nível das alterações das relações humanas, refere-se a uma transformação nas dimensões de tempo e espaço entre as pessoas e lugares, e entre organizações, instituições, nações e culturas ( $p$. 87, tradução nossa).

Os autores sublinham também outras mudanças sociais, aproveitando a teorização acerca da transformação da intimidade (Transformation of Intimacy), desenvolvida por Anthony Giddens. Atribuem-se a essa transformação acontecimentos como a revolução sexual no final dos anos 60 , os movimentos feministas no início dos anos 70 e, principalmente, a suposta crise do núcleo familiar e do casamento. É relevante destacar a transformação sofrida pela instituição família: desenvolveram-se novos e flexíveis arranjos familiares, casais sem matrimônio, casais homossexuais, casamentos abertos, famílias nas quais os avós assumem o papel dos pais. Considerando tais transformações, os autores referem-se a uma intimidade móvel. A Intimidade em condições de intensa mobilidade torna-se flexível, transformável e negociável (p. 90, tradução nossa).

O processo de construção da identidade merece destaque nesse capítulo. No contexto de mobilidade, a identidade também assume caráter transitório. Vivendo em mundo com fronteiras facilmente transponíveis, com um grande número de informações disponíveis, o indivíduo é confrontado com um complexo arranjo de escolhas, sem ter nenhuma dica de que decisão deve tomar. Os autores conduzem bem a argumentação, aproveitando ideias de Anthony Giddens, Ulrich Beck, Michel Foucault, Luce Irigaray entre outros. 
O sexto capítulo, Consuming to excess, revisita de maneira bastante interessante a questão do consumo no mundo contemporâneo. Assuntos trabalhados nos dois capítulos anteriores, como o habitus da elite global (capítulo 4) e processo de construção de identidade (capítulo 5), são inteligentemente conjugados nesse momento. Ao falar em cultura de consumo, os autores partem da premissa de que as identidades já não são formadas apenas pelo trabalho ou pelo pertencimento a determinada classe social, mas, principalmente, através de compra e utilização do capital simbólico de bens de consumo e serviços.

Para evidenciar a relação existente entre a cultura de consumo e a questão das mobilidades, os autores chamam atenção para alguns pontos, a princípio, óbvios mas que não costumam frequentar as análises sobre as práticas de consumo. Primeiramente, os objetos manufaturados precisam ser transportados para serem consumidos. Segundo, há grandes centros de consumo espalhados no mundo que atraem multidões; além de as pessoas transportarem-se até esses destinos, elas próprias encarregam-se de movimentar as mercadorias adquiridas, levando-as para suas casas. Terceiro, os meios de transporte são também bens de consumo, desde os cavalos até os carros e os jatos particulares. Quarto, no que diz respeito a serviços, é necessária a locomoção do prestador ou do consumidor do serviço. Quinto, alguns lugares são referências de determinados tipos de serviços, o que gera considerável fluxo de pessoas. Por último, os lugares não são, necessariamente, simbolicamente fixos; sendo possível aproximarem-se ou afastarem-se dos centros da vida cultural. Os autores aludem às favelas cariocas, que por muito tempo eram tratadas como cancros da cidade e hoje, segundo muitos turistas, constituem o roteiro mais $\mathrm{CoO} /$ do Rio de Janeiro. Dessa maneira, considera-se que os lugares em si podem também estar em movimento. 
Cabe destacar também a perspicaz abordagem que os autores fazem sobre o consumo de lugares. O consumo do lugar diz respeito a um conjunto complexo de múltiplas camadas de práticas sociais, estendidas no tempo e no espaço, envolvendo o consumo de muitos objetos e serviços da localidade referida.

Ainda que tais questões sejam relevantes, o principal ponto destacado no capítulo é o consumo excessivo. Os autores retomam a análise de Thorstein Veblen em relação ao consumo desperdiçador (wasteful consumption). Se Veblen aplicava essa noção às práticas de consumo do indivíduo, os autores de Mobile Lives estendem-na às cidades, regiões, sociedades, que tornaram-se centros de produção e consumo desperdiçador.

No último capítulo, Contested futures, com base no que construíram nos capítulos anteriores, os autores discutem quatro possíveis cenários para 2050. Esses cenários são parte de um programa de previsão do governo do Reino Unido (Foresight Programme) e foram desenvolvidos por um conjunto de especialistas.

O primeiro cenário é o Perpetual motion, que descreve um mundo no qual a ideia de vidas móveis ganham contornos extremos, por conta dos avanços tecnológicos em comunicação e transporte. Desenvolver-se-iam novos tipos de combustíveis e veículos e os cidadãos comuns locomoverse-iam quatro ou cinco horas por dia, estando sempre ligados com os seus mini aparelhos inteligentes. A viagem interespacial seria uma realidade. $\mathrm{E}$ por mais que houvesse um significativo avanço em relação às tecnologias de comunicação à distância, elas não substituiriam a viagem física. Os autores afirmam que esse cenário é improvável e lembram que já foi descrito como uma visão Star Trek do futuro. Consideram ainda que nesse cenário o capital de rede seria a principal causa de desigualdade social.

O segundo cenário apresentado é o Local sustainability, que baseiase em uma realidade de rede de comunidades auto independentes, nas 
quais as pessoas vivem, trabalham e divertem-se. Nesse cenário, a questão da sustentabilidade seria de suma importância e a sociedade teria que acostumar-se à filosofia do small is beautiful. Os autores até dizem que esse cenário é possível, porém improvável, pois demandaria reestruturação massiva das atividades econômicas e a desglobalização da vida econômica, financeira e social.

O terceiro cenário é o Regional warlordism, que consistiria em uma realidade de barbárie generalizada. Por conta de intermitentes guerras por petróleo e água, os sistemas de mobilidade, energia e comunicação entrariam em colapso. Os recursos seriam monopolizados por caudilhos (warlords) e as disputas seriam constantes, fazendo as nações ricas fecharem-se em fortalezas. Esse cenário é comparado com o filme distópico Mad Max 2. Os autores alegam que é um futuro provável, porém não desejável.

O quarto cenário, Digital Network, prevê um futuro de proeminente avanço tecnológico, no qual as emissões de monóxido de carbono seriam rigidamente controladas. Os veículos seriam movidos por baterias e poderiam ser alugados, tais como as bicicletas de Paris ou Barcelona (e por que não do Rio de Janeiro?). As viagens físicas seriam substituídas pelas viagens virtuais, já que novos dispositivos poderão simular uma copresença virtual. Os autores acreditam que esse cenário é tampouco provável, principalmente por conta da implementação dessa infraestrutura ser muito cara e por ferir liberdades civis.

Elliott e Urry consideram ainda que todos esses cenários trariam sérios prejuízos e que nenhum deles é simplesmente preferível ou tem maior probabilidade de ocorrer. Os autores optam por não fazer previsões a tão longo prazo, porém apostam que o neoliberalismo ainda continuará controlando as agendas econômica e política.

A título de curiosidade, destaca-se que ao longo do livro os autores usam a expressão on the move 52 vezes. Pessoas, negócios, objetos, 
identidades, ideias ganham caráter transitório, fugidio. Talvez seja esse o maior legado de Mobile Lives: registrar realidades nas quais a mobilidade não é somente pano de fundo, mas elemento principal. Mobile Lives como já sugerido no início - reitera o Mobilties, reforçando o paradigma das mobilidades empiricamente. Nesse quesito, o livro não é uma novidade, apenas desenvolve contundentemente as questões já trabalhadas. Todavia, isso não deprecia o trabalho feito por Elliott e Urry; é uma leitura imprescindível para interessados em inteirar-se dos debates acerca do paradigma das mobilidades, independentemente da área de formação.

João Freitas. Mestrando no Programa de Pós-graduação em História, Política e Bens Culturais do Centro de Pesquisa e Documentação de História Contemporânea do Brasil (CPDOC/FGV). $\$ joaofreitas@id.uff.br.

\section{Referências}

1. ELLIOTT, A.; URRY, J. Mobile Lives. London: Routledge, 2010. 194p.

2. URRY, J. O Olhar do turista: lazer e viagem nas sociedades contemporâneas. Tradução: Carlos Eugênio Marcondes de Moura, 3a. edição. São Paulo: Studio Nobel, SESC, 2001

3. URRY, J. Mobilities. Malden: Polity Press, 2008.

4. URRY, J. Sociology Beyond Societies. Mobilities for the twenty-first century. London: Routlegde, 2000. 